\title{
Farmers' perceptions and attitudes toward forest watershed conservation of the North Selangor Peat Swamp Forest
}

\begin{abstract}
Over the past several decades, the management of forest ecosystem functions through policies such as "command and control" has not been successful, largely because existing policies and legislation for natural resource management are inadequate and often formulated without consulting local communities such as farmers. However, farmers' decisions to participate in natural resource conservation or watershed conservation more particularly are generally influenced by their knowledge of the problems and perceived benefits of conservation. This study focuses on farmers' perceptions and attitudes toward forest watershed conservation in the North West Selangor Peat Swamp forest of Malaysia. A survey questionnaire was administered to 380 paddy farmers at the North West Selangor irrigation scheme. Dates were analyzed using exploratory factor analysis (EFA) and the theory of value and social psychology constructs. The study concludes that farmers have generally positive attitudes toward forest watershed conservation. Therefore, we recommend farmers' involvement in the conservation and management of the North Selangor Peat Swamp Forest (NSPSF).
\end{abstract}

Keyword: Exploratory factor analysis (EFA); Forest management; Perception and attitude; Psychology construct; Social; Watershed conservation 